\title{
The Abrasive Wear of Non-Oxide Structural Ceramics in Wet Environment
}

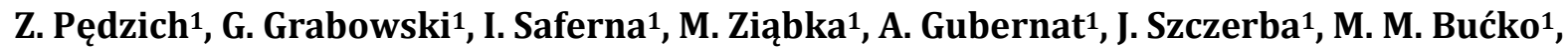 \\ M. Kot ${ }^{2}$ \\ ${ }^{1}$ Department of Ceramics and Refractory Materials, AGH-University of Science and Technology, Krakow, Poland \\ ${ }^{2}$ Department of Machine Design and Technology, AGH-University of Science and Technology, Krakow, Poland \\ Email: pedzich@agh.edu.pl
}

Received July 2014

\begin{abstract}
Silicon carbide and silicon nitride are recognized as phases with very good mechanical properties. Many parts of machines and mechanical devices are made of these materials. Particulate composites basing on both mentioned phases have significant potential of properties improvement. The aim of presented work was to check the difference in wear behavior when materials surfaces were attacked by hard, loose particles in wet environment (pulp). Investigations were performed on silicon carbide, silicon nitride and two composites on their matrices. The basic performed test was the Miller Test according to ASTM Standard. The detail microstructural and mechanical characterization of investigated materials was done. Residual stress state caused by coefficients of thermal expansion mismatch was calculated using FEM approach. The second phases for composites were selected to introduce the compressive stress state into the matrix phase. Comparative studies of abrasive wear of "pure" phases and composites performed showed differences between dominating wear mechanisms. Tests results proved that the influence of the second phase presence in the materials was significant for the wear rate.
\end{abstract}

\section{Keywords}

Abrasive Wear, Miller Test, Silicon Carbide, Silicon Nitride, Residual Stress

\section{Introduction}

The exploitation of many mechanical devices consists in the movement of different parts which are very often exposed on the action of loose hard particles. This may cause many problems according to destruction of surface quality and tightness of part connections. The intensive wear rate in relatively small areas could destroy even big and complicate devices. Ceramic materials are very promising from this point of view. They can offer very good mechanical properties, especially hardness and stiffness which are very important for wear resistance improvement. Additionally, the proper phase composition of ceramic matrix composites can produce in the matrix compressed stresses caused by the mismatch of thermal expansion coefficients of constituent phases [1] [2]. Such stresses could act additionally as toughening mechanism [3] [4] and also improve the abrasive wear resistance.

How to cite this paper: Pędzich, Z., Grabowski, G., Saferna, I., Ziąbka, M., Gubernat, A., Szczerba, J., Bućko, M.M. and Kot, M. (2014) The Abrasive Wear of Non-Oxide Structural Ceramics in Wet Environment. Journal of Materials Science and Chemical Engineering, 2, 9-15. http://dx.doi.org/10.4236/msce.2014.210002 
Generation of mentioned stress state is considered as important factor of strength a fracture toughness improvement. Presented work investigated the role of residual stresses in composites for abrasive wear susceptibility.

\section{Experimental Methods}

\subsection{Starting Powders}

Materials investigated in this work were fabricated utilizing commercially available ceramic powders: SiC powder-Starck UF-15; $\mathrm{Si}_{3} \mathrm{~N}_{4}$ powder-Starck Grade M11 AB168322; $\mathrm{TiB}_{2}$ powder-Starck Grade F-A AB134577. Additionally, some ceramic powders were used as sintering additives for silicon nitride: $\mathrm{Y}_{2} \mathrm{O}_{3}$-Starck Grade C-A AB134554 and $\mathrm{Al}_{2} \mathrm{O}_{3}$-TM-DAR Taimei Chemical. Silicon carbide was sintered with addition of amorphous boron Fluka cat. No. 15580 and carbon introduced as phenolic resin Novolak produced by Nowa Sarzyna (Poland). Four different types of materials were prepared; silicon carbide, silicon carbide/titanium diboride composite, silicon nitride and silicon nitride/silicon carbide composite. In the paper they are described respectively as: SC, SCTB, SN and SNSC.

\subsection{Preparation of Sinters}

Silicon carbide powder was prepared for sintering by addition of $0.5 \%$ of amorphous boron and $3 \%$ of carbon introduced as the phenolic resin into SiC powder [5] [6] and homogenized by 24 hour mixing in ball mill using $10 \mathrm{~mm} \mathrm{SiC} \mathrm{balls.} \mathrm{Sintering} \mathrm{of} \mathrm{SC} \mathrm{samples} \mathrm{was} \mathrm{conducted} \mathrm{in} \mathrm{hot-press} \mathrm{(Thermal} \mathrm{Technology)} \mathrm{with} \mathrm{graphite}$ heating element, in argon atmosphere, under the pressure of $25 \mathrm{MPa}$, at $2150^{\circ} \mathrm{C}$ with 1 hour soaking time at the maximum temperature. Sintered bodies of SC were $10 \mathrm{~mm}$ high and $75 \mathrm{~mm}$ in diameter. These dimensions were also achieved for the rest of investigated materials samples.

Silicon carbide/titanium diboride composite (SCTB) powder was prepared by mixing of $\mathrm{TiB}_{2}$ powder with $\mathrm{SiC}$ and sintering additives in the same condition as $\mathrm{SiC}$ powder. The volumetric ratio of silicon carbide to titanium diboride was 90:10. Sintering conditions of SCTB material was the same as SC one.

Silicon nitride powder (SN) was prepared for sintering by addition of sintering aids-3\% of $\mathrm{Y}_{2} \mathrm{O}_{3}$ and $4.6 \%$ of $\mathrm{Al}_{2} \mathrm{O}_{3}$ [7]. Homogenization of powders was conducted in the ball mill using the same parameters and conditions as for preparation SiC powder. The composite silicon nitride silicon carbide powder SNSC was prepared in the same way. The volumetric ratio of silicon nitride to silicon carbide was 90:10.

Sintering of SN and SNSC samples was conducted in Thermal Technology hot-press with graphite heating element, in argon atmosphere, under the pressure of $25 \mathrm{MPa}$, at $1650^{\circ} \mathrm{C}$ with 1 hour soaking time at the maximum temperature.

After sintering apparent densities of samples were determined by hydrostatic weighing. Relative densities were calculated for each sample as the ratio of apparent density to the theoretical one. Theoretical densities were calculated using the producers values for individual phases and the authors knowledge about phase content of materials. Samples for wear tests were cut using Struers equipment.

The residual stress state in sintered bodies caused by the mismatch of thermal expansion coefficients of constituent phases was calculated using Taya model [8].

\subsection{Mechanical Properties Characterization}

Basic mechanical properties of sintered bodies were determined using commonly used methods. The data for strength $\sigma$ analysis were collected from the four-point bending tests made on $45 \times 4 \times 3 \mathrm{~mm}$ bars (Zwick- Roel Z2.5). For each material type 5 samples were tested. Hardness was measured using indenter with Knoop's geometry. The applied load was $9.81 \mathrm{~N}$ in each case. The mean value of $H K$ was calculated from 10 independent measurements. The fracture toughness $K_{I C}$ was determined by the Vickers indentation method, based on Niihara calculation model and Palmqvist crack model, using Nanotech MV-700 equipment. The load for $K_{I c}$ calculations was $98.1 \mathrm{~N}$. The mean value of $K_{I c}$ was calculated from 5 independent indentations. Microstructural observations of worn surfaces were performed with SEM equipment of Nova Nano 200 produced by FEI.

\subsection{Miller Test}

The abrasive wear susceptibility in water suspension of hard particles (slurry) was determined utilizing partially the Miller Test [9] which is usually predicted determine abrasive properties of slurry in relation to particular 
material (Miller Number). The Nova Werke AG apparatus was utilized. In presented paper authors established the slurry parameters and made tests with the same slurry for different materials. The slurry content was $200 \mathrm{~g}$ of distilled water and $200 \mathrm{~g}$ of $\mathrm{SiC} 80$ (with the grain size ranging in 160 - 200 micrometers). The test duration was 6 hours for each material. Two different samples were tested for each material type. Actually, authors determined the Slurry Abrasion Response of Materials (SAR Number). The wear kinetics was calculated as VLR Number (volume loose rate) from diagrams of wear prepared after each 2 hours of test according to procedures described in the standard (Figure 1).

\section{Results}

Table 1 summarizes density and porosity data of all investigated materials.

Theoretical values of densities for each materials were calculated taking into account the real content of main phases and also the amount of sintering additives (carbon and boron for SiC basing materials and alumina and yttria for $\mathrm{Si}_{3} \mathrm{~N}_{4}$ basing materials). All of them were relatively good densified, porosity was limited to the closed one only. It is worth to noticed that composites were better densified than pure matrices phases.

The residual stresses values state in composites were collected in Table 2. In both composites the dispersed phase caused compressive stresses in the matrix due to their higher coefficient of thermal expansion when compared to the matrix. Such stress state could be an important factor for mechanical properties (strength an fracture toughness) improvement. The mean values of stresses in investigated composites were distinctly (more than $500 \%$ ) different. Silicon carbide matrix was compressed with mean value exceeded $250 \mathrm{MPa}$. In comparison, silicon nitride one was compressed "slightly" with the mean pressure of less than $50 \mathrm{MPa}$.

Data from Table 3 illustrated that such state of stresses influenced distinctly strength and fracture toughness of composites. The improvement of SCTB parameters compared to SC was noticeable in opposition to SN and SNSC pair.

Results of wear test were collected at Table 4 and Table 5. In Table 4 the volumetric wear of all investigated materials was collected. Measurements were made after each 2 hours of test duration. Results indicate that all materials worn out in monotonous way as it is clearly illustrated in Figure 2.

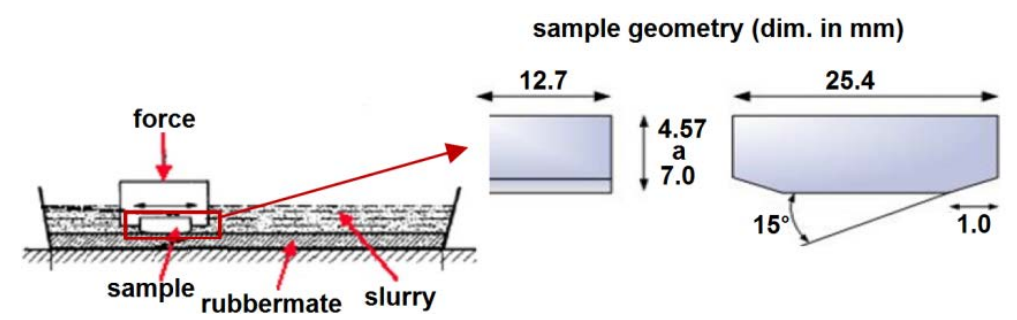

Figure 1. The Miller Test apparatus diagram and the sample geometry [10].

Table 1. Densities and porosity of sintered samples.

\begin{tabular}{ccccc}
\hline \multirow{2}{*}{ Sample } & \multicolumn{3}{c}{ Density } & $\begin{array}{c}\text { Total por., \% } \\
\pm \text { less than } 0.005\end{array}$ \\
\cline { 2 - 4 } & Theor., g/ $\mathrm{cm}^{3}$ & Apparent, g/cm ${ }^{3} \pm 0.01$ & Relative, \% \pm less than 0.005 & 3.27 \\
SC & 3.210 & 3.105 & 96.73 & 2.10 \\
SCTB & 3.304 & 3.270 & 97.90 & 3.18 \\
SN & 3.296 & 3.195 & 96.82 & 2.73 \\
SNSC & 3.291 & 3.201 & 97.27 & \\
\hline
\end{tabular}

Table 2. Calculated values of residual stresses in composites.

\begin{tabular}{ccc}
\hline Composite material & Mean value of compressive stress in matrix, MPa & Mean value of tensile stress in inclusions, MPa \\
\hline SCTB & -258 & 2322 \\
SNSC & -46 & 402 \\
\hline
\end{tabular}


SiC

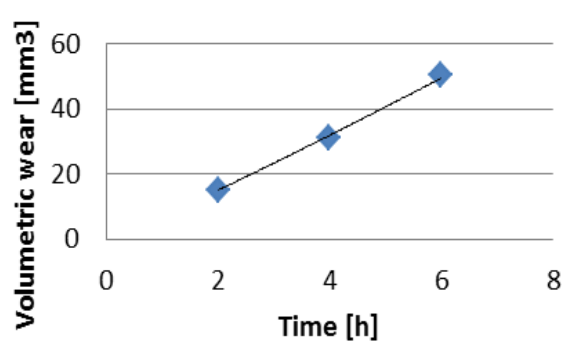

$\mathrm{Si}_{3} \mathrm{~N}_{4}-\mathrm{SiC}$

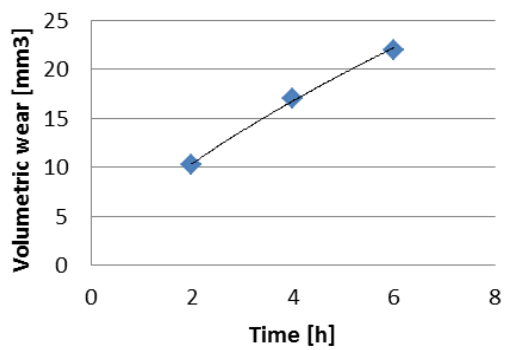

Figure 2. Typical plots of volumetric wear during Miller Test (for SC and SNSC samples).

Table 3. Mechanical properties of sintered samples.

\begin{tabular}{cccc}
\hline Sample & Vickers hardness HK, GPa & Fracture toughness $K_{I c}$, MPam $^{0.5}$ & Bending strength $\sigma$, MPa \\
\hline SC & $19.5 \pm 1.2$ & $4.6 \pm 0.7$ & $351 \pm 45$ \\
SCTB & $18.7 \pm 0.5$ & $5.3 \pm 0.6$ & $402 \pm 50$ \\
SN & $13.1 \pm 0.2$ & $5.1 \pm 0.5$ & $613 \pm 40$ \\
SNSC & $14.1 \pm 0.7$ & $5.2 \pm 0.4$ & $589 \pm 35$ \\
\hline
\end{tabular}

\pm denotes the standard deviation.

Table 4. Results of the volumetric wear during Miller Test.

\begin{tabular}{cccc}
\hline Sample & $\begin{array}{c}\text { Volumetric wear after } \\
2 \text { hours of test, } \mathrm{mm}^{3}\end{array}$ & $\begin{array}{c}\text { Volumetric wear after } \\
\text { 4 hours of test, } \mathrm{mm}^{3}\end{array}$ & $\begin{array}{c}\text { Volumetric wear after } \\
6 \text { hours of test, } \mathrm{mm}^{3}\end{array}$ \\
\hline SC & $17.84 \pm 3.76$ & $34.55 \pm 5.18$ & $51.73 \pm 1.83$ \\
SCTB & $16.61 \pm 0.82$ & $32.57 \pm 1.83$ & $51.87 \pm 1.73$ \\
SN & $12.13 \pm 0.55$ & $21.14 \pm 2.35$ & $34.98 \pm 5.84$ \\
SNSC & $10.20 \pm 0.10$ & $18.60 \pm 2.14$ & $24.70 \pm 3.70$ \\
\hline
\end{tabular}

\pm denotes the standard deviation.

Table 5. Results of SAR and VLR Numbers calculatins.

\begin{tabular}{ccc}
\hline Sample & SAR number & VLR number \\
\hline SC & $155 \pm 10$ & $8.55 \pm 0.58$ \\
SCTB & $149 \pm 7$ & $8.19 \pm 0.38$ \\
SN & $98 \pm 14$ & $5.42 \pm 0.75$ \\
SNSC & $75 \pm 14$ & $4.14 \pm 0.76$ \\
\hline
\end{tabular}

\pm denotes the standard deviation.

Values of SAR and VLR numbers collected in Table 5, as calculated on the basis of volumetric wear data confirm differences in wear process of investigated materials.

The level of degradation was significantly different for both investigated groups of materials. SN and SNSC materials were distinctly less susceptible for degradation.

SN matrix was about 32\% more resistant for applied wear process than SC. Behaviour of SNSC composite showed the mentioned property better for the $30 \%$ than SN material.

In $\mathrm{SiC}$ basing materials the wear behaviour improvement did not take place for composite. SC and SCTB have practically the same wear parameters.

The highest values of compressive stresses in the silicon carbide matrix were calculated for SCTB material level results suggest that the stress state has not the decisive influence on wear rate decreasing in composites. 
This statement was confirm by the observation that the lowest level of wear susceptibility was detected for composite with the lowest level of residual stresses.

Wear resistance under Miller Test was not correlated with mechanical properties. Materials with highest hardness (SC, SCTB) were the worse during the wear test. Fracture toughness improvement (SC $\rightarrow$ SCTB) did not influence positively wear resistance. Changes in bending strength also could not be correlated with wear behavior. Analysis of microstructures in Figures 3-6 showed that SiC basing materials had distinctly different worn surface when compared to $\mathrm{Si}_{3} \mathrm{~N}_{4}$ basing materials. SC and SCTB materials surfaces were much rougher than SN and SNSC ones. It suggested that for wear resistance of SC and SCTB materials the decisive factor was $\mathrm{SiC}$ matrix resistance. The high residual stresses level was practically not important for wear rate of composite. The main reason of SC and SCTB material degradation during Miller Test were local damages in small areas crushed single grains of $\mathrm{SiC}$ into small debris. It the most probably caused higher friction and intensified damage forces on the surface.

For both investigated silicon nitride basing materials measured wear resistance was much lower than observed for silicon carbide basing ones. The most important observation was that in this case the composite material was distinctly better than pure matrix.

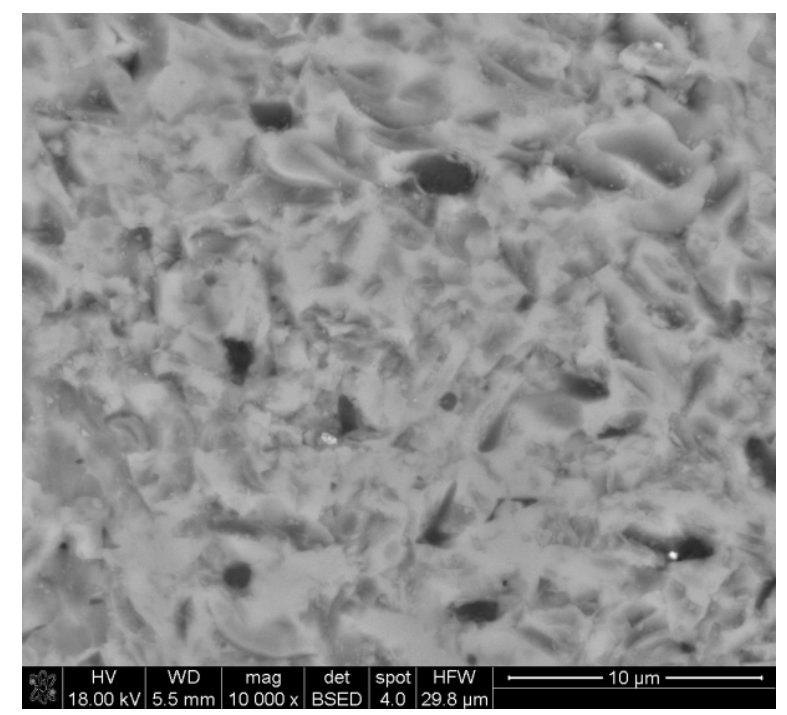

Figure 3. SEM image of worn SC sample.

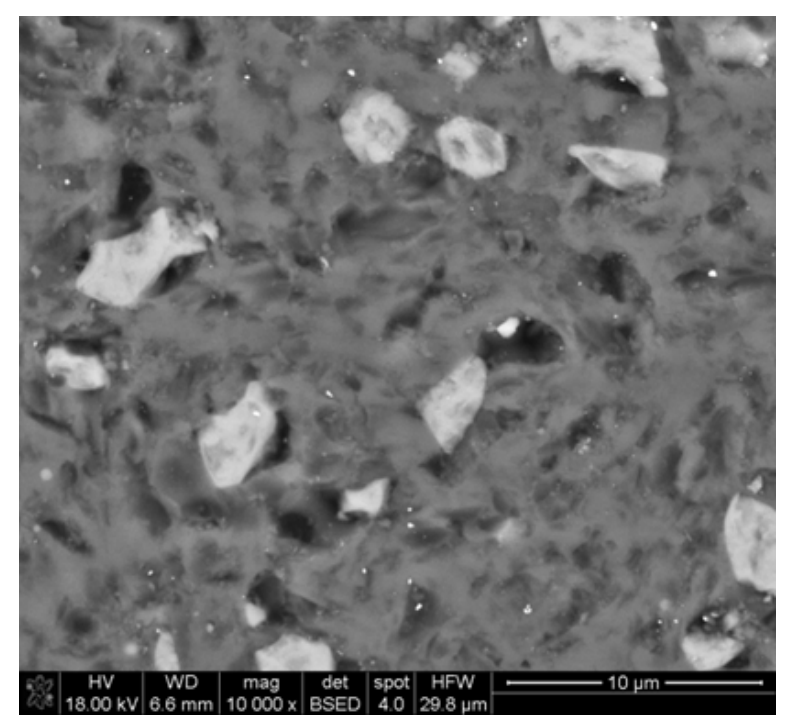

Figure 4. SEM image of worn SCTB sample. 


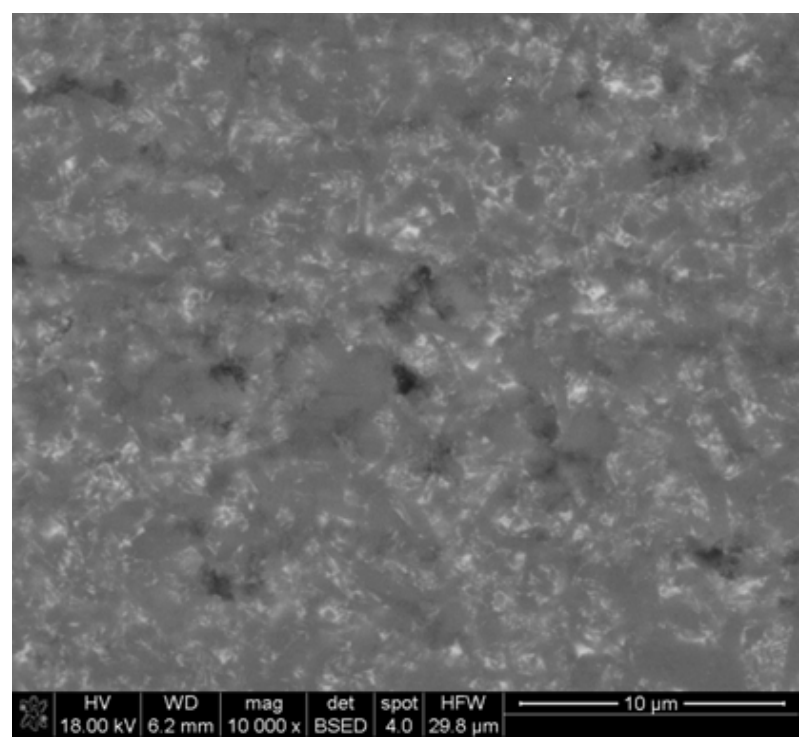

Figure 5. SEM image of worn SN sample.

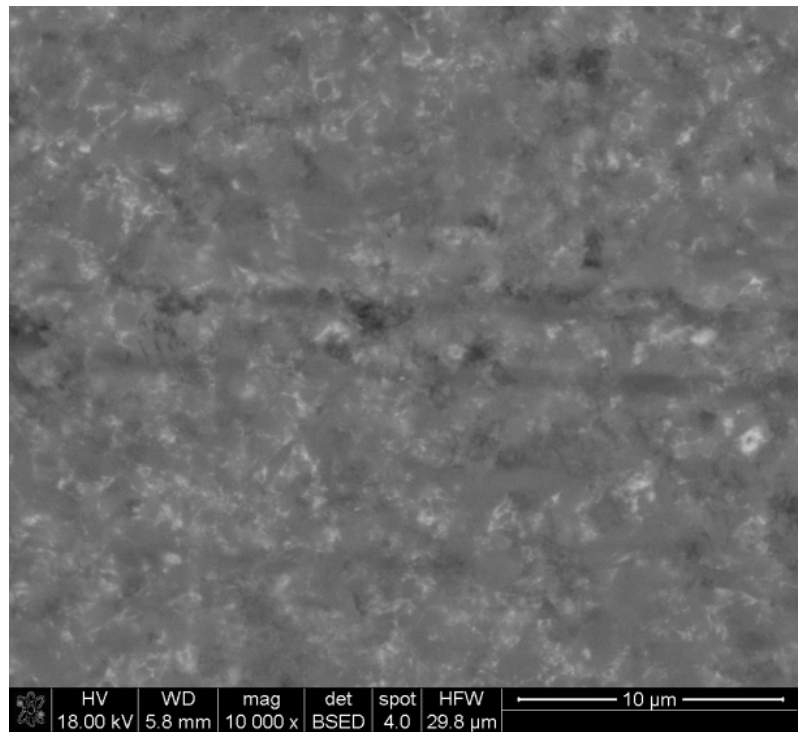

Figure 6. SEM image of worn SNSC sample.

\section{Summary}

Although, manufacturing of particulate composites could be effective way to mechanical properties improvement in structural ceramic sinters, performed experiments proved that such mechanism is not always successful for some useful properties which depend on many different factors. For two investigated pairs of materials (SC; SCTB and SN; SNSC) the presence of compressive stress in the matrix acted in different way.

\section{Acknowledgements}

The work was financially supported by the Polish State National Centre for Research and Development under Programme INNOTECH-K2/IN2/16/181920/NCBR/13.

\section{References}

[1] Grabowski, G. and Pędzich, Z. (2007) Residual Stresses in Particulate Composites with Alumina and Zirconia Matrices. 
Journal of the European Ceramic Society, 27, 1287-1292. http://dx.doi.org/10.1016/j.jeurceramsoc.2006.04.096

[2] Grabowski, G. and Stobierski, L. (2005) Influence of Thermal Stresses on Mechanical Properties of Ceramics Particulate Composites. Ceramika/Ceramics, 91, 627-634.

[3] Jiao, S., Jenkins, M.L.L. and Davidge, R.W.W. (1997) Interfacial Fracture Energy-Mechanical Behaviour Relationship in $\mathrm{Al}_{2} \mathrm{O}_{3} / \mathrm{SiC}$ and $\mathrm{Al}_{2} \mathrm{O}_{3} /$ TiN Nanocomposites. Acta Materialia, 45, 149-156. http://dx.doi.org/10.1016/S1359-6454(96)00168-1

[4] Ohji, T., Jeong, Y.-K., Choa, Y.-H. and Niihara, K. (1998) Strengthening and Toughening Mechanisms of Ceramic Nanocomposites. Journal of the American Ceramic Society, 60, 1453-1460. http://dx.doi.org/10.1111/j.1151-2916.1998.tb02503.x

[5] Stobierski, L. and Gubernat, A. (2003) Sintering of Silicon Carbide I. Effect of Carbon. Ceramics International, 29, 287-292. http://dx.doi.org/10.1016/S0272-8842(02)00117-7

[6] Stobierski, L. and Gubernat, A. (2003) Sintering of Silicon Carbide II. Effect of Boron. Ceramics International, 29, 355-361. http://dx.doi.org/10.1016/S0272-8842(02)00144-X

[7] Hayashi, T., Munakata, H., Suzuki, H. and Saito, H. (1986) Pressureless Sintering of $\mathrm{Si}_{3} \mathrm{~N}_{4} \mathrm{with} \mathrm{Y}_{2} \mathrm{O}_{3}$ and $\mathrm{Al}_{2} \mathrm{O}_{3}$. Journal of Materials Science, 21, 3501-3508. http://dx.doi.org/10.1007/BF02402994

[8] Taya, M., Hayashi, S., Kobayashi, A.S. and Yoon, H.S.S. (1989) Toughening of a Particulate-Reinforced/CeramicMatrix Composite. Journal of the American Ceramic Society, 73, 1382-1391. http://dx.doi.org/10.1111/j.1151-2916.1990.tb05209.x

[9] Test Method for Determination of Slurry Abrasivity (Miller Number) and Slurry Abrasion Response of Materials (SAR Number), ASTM G75-95 Standard.

[10] User Manual of Nova Werke AG device for Miller Test. 